\title{
A missão gastronômica francesa no Brasil dos anos $1970^{1}$
}

The French Gastronomic Mission in Brazil in the 1970 s

Débora Previatti*

\section{Resumo}

$\mathrm{O}$ artigo aborda a passagem de chefs da alta gastronomia francesa pelo Brasil na década de 1970, bem como a sua repercussão na imprensa e na cultura dos restaurantes da época (italianos, em particular). Liderada por Paul Bocuse, a iniciativa visava a difusão das ideias da nouvelle cuisine e deu início a uma nova "missão francesa", a exemplo das missões artísticas e intelectuais anteriormente empreendidas em terras brasileiras. Nas décadas seguintes, de 1980 e 1990, outras missões gastronômicas se sucederam, marcadas pela busca de formação de alianças, sobretudo por meio de "gastrodiplomacia".

Palavras-chave: Missão francesa; Engajamento gastronômico; Nouvelle Cuisine; Paul Bocuse; Brasil; Século XX.

\section{Abstract}

The article addresses the passage of French haute cuisine chefs through Brazil in the 1970s, as well as its repercussion in the press and in the culture of the restaurants of the time (Italian, in particular). Led by Paul Bocuse, the initiative aimed to spread the ideas of the nouvelle cuisine and started a new "French mission", like the artistic and intellectual missions previously undertaken in Brazilian lands. In the following decades, 1980s and 1990s, other gastronomic missions followed, marked by the search for alliances, especially through "gastrodiplomacy".

Keywords: French mission; Gastronomic engagement; Nouvelle Cuisine; Paul Bocuse; Brazil; $20^{\text {th }}$ Century.

\section{INTRODUÇÃO}

A despeito da consolidação dos Estados nacionais, há a permanência da circulação de bens, pessoas e modelos (Heilbron; Jeanpierre; Guilhot, 2009), notadamente impulsionada pelo próprio colonialismo (Steinmetz, 2007). Neste contexto, obras como as de Casanova (2015) e Sapiro (2016) vêm contri-

\footnotetext{
* Universidade de São Paulo (USP), São Paulo, SP, Brasil. deborapreviatti@gmail.com <https://orcid. org/0000-0002-8224-904X>
} 
buindo para se pensar a teoria dos campos em uma perspectiva que contempla a hierarquia internacional e as desigualdades de poder entre as culturas. Alguns trabalhos mostram que a relação Norte-Sul é central à compreensão da internacionalização, e que a América Latina é um foco analítico inescapável (Beigel, 2014; Abarzúa Cutroni, 2016; Quesada, 2015).

Na década de 1970, um grupo de renomados chefs franceses veio, em caráter missionário, ao Brasil. ${ }^{2}$ Essa visita deu início a uma nova "missão francesa”, a exemplo das missões artísticas (Taunay, 1983; Schwarcz; Simioni, 2016) e intelectuais (Miceli, 2001; Garcia Jr., 2009; Suppo, 1995; 2000) anteriormente empreendidas em terras brasileiras. Compreendemos aqui que o objetivo da difusão dos princípios da Nouvelle Cuisine parte da premissa da instauração de uma geografia de poder, revelada por uma relação hierarquizada entre centro e periferia. O primeiro é definido como o polo de criação artística ou intelectual e a segunda, por um "atraso", dado o seu afastamento do "centro". Ao mesmo tempo, a transmissão de padrões do "centro" à "periferia" é marcada por conflitos e envolve dominação simbólica. ${ }^{3}$

Nas últimas décadas, os chefs, aliando as credenciais de autoridade e de experts, passaram a ocupar uma posição estratégica de intermediários culturais (Piper, 2015; Barnes, 2017) e, assim, a exercer papel mediador das práticas culinárias no espaço doméstico, atuando diretamente na produção simbólica de valor e de gosto. A diversidade de figuras midiáticas do chef de cozinha também faz ganhar corpo uma visão de um chef engajado e "salvador" (Pagès, 2018). Tal imagem social, construída, sobretudo, por meio da escrita, agrega prestígio, legitima e consagra carreiras e trajetórias sociais. Com efeito, a gastronomia, desde o seu surgimento, dependeu amplamente da escrita, sendo que os textos foram responsáveis por transformar a produção e o consumo de alimentos em um fenômeno intelectual (Ferguson, 2004). No processo de autonomização do campo gastronômico francês, o conjunto de escritos propunha um discurso culinário expansivo e nacionalizante, e foi o que assegurou a autonomia do campo (Ferguson, 1998).

Partimos, nesta investigação, da premissa de que a comida e as práticas em torno da cozinha constituem marcadores de status (Bourdieu, 2011). Consideramos, igualmente, que o tipo de capital culinário adquirido varia de acordo com as relações de dominação e conforme a posição ocupada por um indivíduo no espaço social em questão (Naccarato; Lebesco, 2012). Conforme 
Pinto (2013), o estudo das práticas de um agente ou de um grupo só adquire sentido quando estas são apreendidas diferencialmente, nos espaços sociais nos quais esses agentes atuam. Quando tais práticas envolvem diversos domínios, elas se unem por relações sistemáticas, e as variáveis mobilizadas na análise não são fatores unívocos e simples. Este artigo discute certas especificidades da intervenção de um grupo de chefs em solo brasileiro, em caráter de "missão". Engajamentos, investimentos "gastrodiplomáticos" e lutas pela produção de discursos legítimos no espaço social se revelam estratégias de reprodução de famílias da elite gastronômica francesa, fundamentadas por meio da classificação, da apropriação e da hierarquização de elementos ligados ao popular e à periferia.

\section{Metodologia de Pesquisa}

A pesquisa envolveu a combinação de diferentes técnicas e fontes, a favor da diversificação de métodos, a fim de fornecer maiores subsídios para possibilidades de comparação e de objetivação (Combessie, 2007). Foi realizado levantamento quali-quantitativo de materiais a partir de revistas não-especializadas de grande circulação, garantindo uma variabilidade interna, a fim de permitir a comparação em termos geracionais, de gênero e de classe social. A aliança de métodos qualitativos e quantitativos, ao proporcionar que o pesquisador tenha uma posição mais “justa” em relação ao objeto de pesquisa, torna-se fundamental em termos de postura científica (Dietrich-Ragon; Loison-Leruste; Roupnel-Fuentes, 2012). A escolha de revistas não-especializadas se deveu ao fato de as especializadas terem sido criadas apenas nas décadas mais recentes e, portanto, posteriormente à consolidação da profissão de cozinheiro no país.

O empreendimento metodológico consistiu fundamentalmente em método iconográfico, mobilizando-se como fontes textos e imagens veiculados em reportagens, editoriais, capas e propagandas de sete revistas brasileiras de circulação nacional - Marie Claire Brasil, Claudia, Nova, Capricho, Playboy, Veja e IstoÉ - e de uma revista francesa, Marie Claire France. Ao todo, foi realizado o folheio de 2.321 edições, publicadas entre as décadas de 1960 e 2010, no caso brasileiro, e entre 1930 e 2010, no caso francês. Foram investigadas simultaneamente as imagens e as estruturas narrativas que as acompanhavam, 
pela importância da descrição conferida a cada produto cultural. Dado o valor da linguagem na elucidação da lógica de todo o campo de produção simbólica, produziu-se, em conjunto, uma análise filológica do material coletado (Panofsky, 1983).

Quadro 1: Número de edições analisadas e número de achados por revista

\begin{tabular}{|c|c|c|}
\hline Revista & $\begin{array}{l}\mathrm{N}^{\circ} \text { edições } \\
\text { consultadas }\end{array}$ & $\begin{array}{l}\text { Total de } \\
\text { achados }\end{array}$ \\
\hline Veja & 864 & 140 \\
\hline Claudia & 488 & 342 \\
\hline IstoÉ & 482 & 107 \\
\hline Marie Claire Brasil & 120 & 75 \\
\hline Capricho & 59 & 03 \\
\hline Playboy & 33 & 20 \\
\hline Nova & 26 & 16 \\
\hline Marie Claire France & 249 & 186 \\
\hline Total & 2.321 & 889 \\
\hline
\end{tabular}

Fonte: A autora.

A investigação aqui proposta se insere na agenda internacional de pesquisa sobre as dinâmicas da internacionalização dos campos ${ }^{4}$, sobre a circulação internacional de ideias (Bourdieu, 2002; Dezalay; Madsen, 2013) e sobre a sociologia da edição e da tradução. À luz das contribuições teórico-metodológicas de Panofsky $(1983,2001)$ e de Bourdieu (2011), foram analisadas as interações entre diferentes categorias - gênero, território, geração, classe social e outros -, bem como entre fenômenos distintos do processo significativo das práticas culturais em jogo e da hierarquização de tais práticas, a qual repercute na formação de polarizações no interior do campo. A atribuição de tais significados está condicionada a códigos e convenções sociais, vigentes em espaço e tempo determinados. 
Paul Bocuse e "LA BANDE" No Brasil

DOS ANOS 1970: UMA “MISSÃO FRANCESA"

Em 1975, o chef francês Paul Bocuse (1926-2018) recebeu a condecoração de Chevalier de la Légion d'honneur, a mais alta distinção honorífica francesa. No mesmo ano, o referido chef renomado desembarcava em terras brasileiras. Em um roteiro de cinco dias, incluindo São Paulo, Rio de Janeiro e Brasília, o "papa" da gastronomia francesa fez um levantamento das condições para a organização de um Festival da Gastronomia Francesa no Brasil. A intenção era que o evento ocorresse cerca de três a oito meses mais tarde, com a participação de doze cozinheiros de seu restaurante. Bocuse também divulgava que possuía planos a concretizar em solo brasileiro.

Revista Veja - A repercussão desta sua visita não faz pensar em planos para uma futura casa brasileira?

Bocuse - Sim, eu penso nisso. Estou, é claro, representando a cozinha francesa, mas divulgo também o nome de Paul Bocuse, que inclui uma pequena produção de vinhos. Eu penso não só em vir a exportar esses vinhos para o Brasil como em abrir um restaurante por aqui, talvez no Rio (Sr. Restaurante, 1975b, p. 42).

Nas idas ao Brasil na década de 1970, Bocuse vinha acompanhado de um ou outro membro do que se intitulou de "La bande à Bocuse", um grupo de amigos e aliados, que contava com os nomes, além do próprio Bocuse, de Jean e Pierre Troisgros, Paul Haeberlin, Alain Chapel, Louis Outhier, René Lasserre, Pierre Laporte, Gaston Lenôtre, Roger Vergé, Raymond Oliver, Charles Barrier e Michel Guérard. No Brasil e em outros países, Bocuse e seu grupo propagavam o seu próprio nome, mas também os princípios da Nouvelle Cuisine. Ao divulgar tais convenções, o chef abordava os novos pilares da cozinha francesa, a qual redirecionaria também toda a gastronomia profissional mundial.

Revista Veja - O que se deve entender, afinal, por uma "nova cozinha francesa"? Bocuse - Antes de mais nada, é uma nova visão do que se deve ser uma refeição. Hoje em dia as pessoas se movimentam pouco, usam o automóvel para tudo, quase não praticam exercícios. Há ainda o fato de que todos, homens e mulheres, têm a preocupação de não engordar, o que muda o antigo conceito do bom gourmet. Agora, esse conhecedor da boa mesa é uma pessoa sensível, que preza o 
próprio físico e cujo paladar está atento ao gosto natural dos alimentos. Então nós, os cozinheiros, e principalmente um grupo dos doze melhores, integrantes da associação da Grande Cozinha Francesa, começamos a redescobrir as qualidades de legumes recém-colhidos, de carnes e peixes não congelados (Sr. Restaurante, 1975b, p. 42).

Em 1977, em outra ocasião, o "papa” da gastronomia veio ao Brasil a convite da revista Claudia e do Serviço Nacional de Aprendizagem (Senac) instituição dedicada à formação profissional de cozinheiros a qual viria a fundar, posteriormente, a maior editora com foco em livros de cozinha. Bocuse circulou pelo país em companhia de Elisabetta Orrico, editora da revista Claudia. Em sua passagem pela região norte do país, no estado do Pará, o chef foi recebido pelas famílias Morelli e Nunes Acatauassu. Na auspiciosa visita, o chef, junto a seu grupo de "missionários", entusiasmado com ingredientes e pratos regionais, aclamou: "Il faut sauver la cuisine brésilienne!". Bocuse referia-se a ingredientes e pratos "autenticamente" brasileiros em desvalorização - produtos "exóticos" os quais, mediante o savoir-faire de chefs, aos olhos estrangeiros, poderiam ser "resgatados" e "convertidos" em "boa cozinha".

Fotografia 1: Bocuse prepara uma de suas receitas na cozinha do Senac.

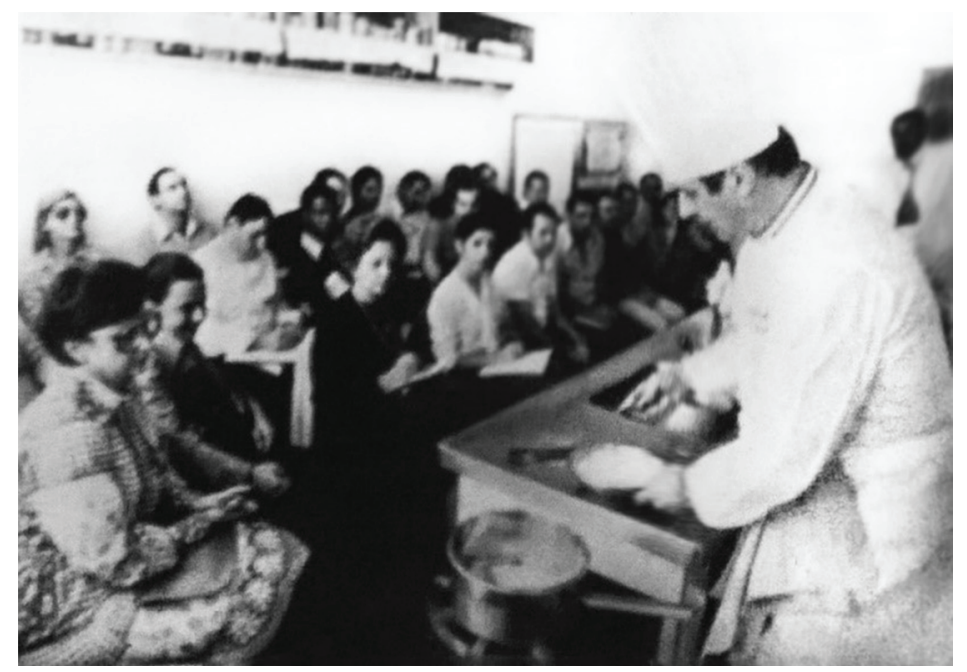

Fonte: Receitas do melhor cozinheiro..., 1977, p. 136. 
A expressão "Nouvelle Cuisine” foi cunhada por Henri Gault e Christian Millau após a ida de ambos ao restaurante Chez Bocuse, onde o chef lhes serviu uma simples salada de vagem acompanhada de tomates, conforme explicam os críticos anos depois (Gault; Millau, 1976). Em seguida, os “inventores” foram encontrar outros cozinheiros que já estariam fazendo a "nova cozinha" sem saber, os irmãos Troisgros, em Roanne, os quais lhes serviram rãs com ervas. Alguns chefs que participaram do movimento da Nouvelle Cuisine posteriormente fariam parte de uma onda de imigração ao Brasil, e comporiam o que se poderia chamar de uma elite gastronômica no país. A grande maioria deles possuía alguma ligação com Bocuse e "La bande". Alguns deles eram eles membros de "La bande", como é o caso de Gaston Lenôtre, que veio ao Rio de Janeiro abrir o restaurante Le Pré Catelan. Outros eram "herdeiros" das principais famílias de renome da gastronomia francesa, como é o caso de Claude Troisgros, ou haviam estagiado com Bocuse em seu restaurante, ficando conhecidos como "les disciples" do "papa" da gastronomia, tais como Laurent Suaudeau e também Claude Troisgros. Em um artigo dedicado ao surgimento histórico da sociologia enquanto campo entre o nacional e o internacional, Gisèle Sapiro nos mostra como o nacional é construído, em certa medida, transnacionalmente, com um enfoque em seus "pais fundadores" (Sapiro, 2018). Da mesma maneira, o espaço gastronômico nacional se desenvolve no Brasil, em grande parte, internacionalmente, por meio de seus "pais fundadores", bem como de seus "discípulos", adeptos conquistados em solo brasileiro e chefs imigrantes que vieram dar continuidade ao legado de famílias da alta cozinha francesa.

Alguns dos diagnósticos dos chefs em missão no Brasil foram os de que os espaços de formação profissional eram escassos e, sobretudo, de que não haviam encontrado, nos profissionais brasileiros da época, uma preocupação em se adequar a códigos, regras e convenções extranacionais. Na visão de Bocuse e de outros chefs renomados, não seguir os pressupostos da Nouvelle Cuisine era um sintoma da desvalorização da cozinha brasileira, que precisava e poderia ser "salva" por meio do savoir-faire de profissionais da alta cozinha francesa. Logo após as visitas a diversos países em caráter missionário, Bocuse e "La bande", a fim de expandirem o seu "império gastronômico" no estrangeiro, passaram a fincar seus alicerces em diversos países, incluindo o Brasil. Em junho de 1980, a revista Marie Claire France publicou uma pequena nota 
sobre o fato de que, pela primeira vez, os chefs renomados franceses realizavam uma assembleia fora da França (Les maitres-cuisiniers de France, 1980). Em 1982, Bocuse, juntamente com dois membros de "La bande", Gaston Lenôtre e Roger Vergé, criavam o Pavillon de France na Disneylândia, na Flórida.

A migração de chefs franceses renomados, sobretudo para a região sudeste do Brasil - particularmente o eixo Rio-São Paulo -, a partir dos anos 1970, teria ocorrido por intermédio de Bocuse e de seus aliados mais fundamentais, os irmãos Troisgros. Claude Troisgros, membro da terceira geração de uma das famílias centrais da elite gastronômica francesa, os Troisgros, teria seguido as recomendações de Bocuse ao decidir migrar para o Rio de Janeiro em 1979, para assumir a liderança do restaurante Le Pré Catelan, a mesma posição que viria a ser ocupada posteriormente por Emmanuel Bassoleil, em 1983. O herdeiro, filho de Pierre Troisgros e neto de Jean Baptiste Troisgros, teria vindo para assumir a reprodução das receitas de Gaston Lenôtre, membro de " $\mathrm{La}$ bande", no âmbito do restaurante aberto em 1976. Claude Troisgros aparece em uma pequena nota biográfica na revista Claudia, três anos depois de sua partida ao Brasil.

\section{O TERROIR BRASILEIRO COMO FONTE DE CRiatividade PARA A Nouvelle CUISINE}

Por influência de fenômenos de repercussão mundial, tais como a Nouvelle Cuisine, a cultura do terroir (Garcia-Parpet, 2004) e o Slow food, a gastronomia profissional mundial passou a valorizar, de modo crescente, alimentos frescos e "locais". O foco passou aos ingredientes, pratos e bebidas "autênticos" de cada país ou região, contribuindo para a apropriação social de novos modelos alimentares (Cardon; Garcia-Garza, 2012; Pulici, 2019; Johnston; Rodney; Szabo, 2012). Nos anos 1980, as cozinhas regionais mudam de status e surge a expressão "Nouvelle Cuisine de terroir", cunhada por Marc de Champerard. As cozinhas "locais" passam a ser vistas como fontes de inspiração para o trabalho de chefs renomados, como forma de atenderem a uma exigência de criatividade na alta gastronomia (Poulain, 2016).

Em virtude da abundância de recursos naturais e da biodiversidade, o Brasil tornou-se visado por chefs estrangeiros. Tal cenário se estruturou principalmente a partir dos anos 1990, quando a agricultura brasileira passou por 
mutações que projetaram o país às principais cadeias globais de valor e a uma imagem de "nouvelle ferme du monde" (Niederle; Schneider, 2018). No final da década, há um grande interesse global pela biodiversidade da América Latina e pelos seus produtos, incluindo países como Brasil, México, Peru e Chile (Bueno, 2016). O Brasil simbolizava um solo amplamente fértil, detentor de grande fonte de matérias-primas, a partir das quais poderiam ser aplicadas as técnicas consagradas internacionalmente pelas escolas e academias. Conforme Drouard (2004), foi graças às associações de produtos, incorporando técnicas e ingredientes estrangeiros, que a Nouvelle Cuisine manteve o seu sucesso. Foi com um enfoque em produtos frescos e regionais que tal movimento levou a uma redefinição do que se concebia como gastronomia. As novas práticas, ancoradas nos princípios do movimento culinário, tidas como de "miscigenação" e de "cruzamento de culturas", prepararam terreno para o nicho que viria a ser conhecido por "cozinha de fusão" e "cozinhas do mundo".

Tal convenção foi um dos fatores que impulsionou uma pluralidade de engajamentos em defesa de ingredientes "autenticamente" brasileiros, "desvalorizados" ou "esquecidos" na memória nacional, tornando-se posteriormente uma das principais bandeiras de alguns integrantes do primeiro estrato geracional de chefs renomados brasileiros. A militância a favor dessa "causa", constituída em marcador distintivo, impulsionou, em boa parte dos casos, a notoriedade de cozinheiros no espaço social gastronômico mundial. O crescimento de preocupações com a ética alimentar e o desenvolvimento sustentável, unidas à institucionalização da agroecologia, também impulsionaram determinados mercados alimentares no Brasil, como o de orgânicos, gerando novos circuitos de comércio. Soma-se a tais fatos a crescente convergência entre o ativismo em benefício da gastronomia local e o militantismo ambiental (Niederle; Schneider, 2018). Tal fenômeno catalisou o desenvolvimento de cozinhas de restaurantes de alta cozinha no país, que dependiam desses produtos e, por consequência, o fortalecimento de nomes de cozinheiros bem reputados, alguns deles tendo atuado como protagonistas de alguns desses engajamentos.

Parte de tal protagonismo se deve a uma crença que se tornou bastante bem fundamentada: de que os chefs lideram um movimento de resgate da cultura local e da cozinha "autenticamente" brasileira, a fim de inserirem-na no circuito gastronômico mundial das grandes cidades ${ }^{5}$ e das capitais culturais ${ }^{6}$, passando assim a serem vistos como "heróis modernos". ${ }^{7}$ Esse "heroísmo", de caráter am- 
bivalente (Pagès, 2018), configura um tipo de engajamento que resulta na acumulação de capital social e é fonte de distinção social. Nesse processo, sucedem a apropriação e a redefinição de pratos e cozinhas "populares", enquanto os discursos dos profissionais ${ }^{9}$ constroem uma identidade regional ou nacional invocando uma "tradição culinária nacional", em consonância com marcadores distintivos vigentes no espaço social gastronômico mundial. Por meio de sua atuação, os chefs teriam o savoir-faire necessário para refinar objetos culinários "populares", sendo capazes de transmutar simbolicamente ${ }^{10}$ tais objetos em produtos culturais determinados, atribuindo a eles a sua assinatura. Poulain (2011) denominou fenômenos como esse de gastronomização das cozinhas "populares", esta acompanhada de crescente patrimonialização da alimentação, segundo a qual os chefs se inscrevem em estratégias e políticas públicas em torno dos patrimônios alimentares (Pagès, 2018).

Ao se conceber que há uma única cozinha "autenticamente" brasileira, a qual seria "influenciada" por diferentes grupos sociais - frequentemente indicados como "raças" ou "etnias" -, tem-se a ideia, em primeiro lugar, de que tal "influência" teria se desenvolvido de forma harmoniosa e pacífica. Abordar a participação de povos fundadores como "vestígios", "contribuições" ou "influências" confere uma visão por demais redutora do processo histórico - hierarquizante, discriminatório, desigual e conflitivo - em que se deu tal participação. Referir-se a uma diversidade única e essencializada acabaria assim por legitimar uma dada ordem social de caráter desigual e hierarquizado (Maciel, 2004). Nas revistas, o diagnóstico de que surgia uma cozinha "autenticamente" brasileira ocasionou novas maneiras de produção das fotografias. Ao mesmo tempo em que o tema da identidade nacional e a estetização dos pratos ganharam papel central nas publicações ligadas à culinária, há a especialização de editores a fim de se enfatizar o acento "brasileiro" das receitas publicadas.

\section{CUISINE À L'HUILE OU CUISINE AU BEURRE? ESTRATÉGIAS DE CONSERVAÇÃO E ESTRATÉGIAS DE SUBVERSÃo}

Na medida em que os chefs franceses chegaram ao Brasil em caráter de desafiadores da cultura legítima, isso despertou a elaboração de estratégias de conservação e de subversão por parte de agentes dominantes e dominados, que marcaram as lutas para a produção de discursos legítimos. Tais agentes pos- 
suíam interesses em comum no país, associando-se em diferentes modalidades de engajamento, o que caracterizou certa "cumplicidade objetiva”. Os conflitos foram manifestos, sobretudo, pela conhecida oposição entre cuisine à l'huile e cuisine au beurre, estabelecida entre aqueles que já estavam no país e os últimos a chegar. Tal oposição foi um recurso mobilizado para circunscrever e distinguir hierarquicamente a cozinha dos recém-chegados (os franceses) daquela dos antigos (os italianos), de modo que a confrontação entre manteiga e azeite de oliva, como ingredientes de referência identitária de cada uma dessas cozinhas, expressava um conflito mais amplo que ganhava corpo naquele momento no Brasil. A chegada de chefs franceses em solo brasileiro simbolizava uma ameaça aos agentes do mercado de restaurantes de inspiração italiana em todo o país, de modo que os italianos já enraizados no Brasil se sentiam atacados pelos pressupostos da Nouvelle Cuisine. O discurso identitário foi, portanto, mobilizado como recurso cultural nas lutas pelo discurso legítimo que se desenrolaram entre italianos e franceses em solo brasileiro.

Nos anos 1970, com a vinda de chefs franceses com objetivos ambiciosos para o Brasil - seja em sua visita missionária ou, posteriormente, através da migração (os quais passavam também a atuar como "âncoras" e correspondentes de chefs radicados na França) -, veio a se instaurar um verdadeiro front de batalha, uma disputa cognitiva acirrada a favor da ocupação dos postos hierárquicos mais altos da alta cozinha no Brasil. Uma disputa central foi travada entre profissionais de restaurantes italianos e franceses. Aproximadamente cem anos antes da missão liderada por Bocuse e "La bande", houve uma imigração italiana significativa ao país. Conforme Collaço (2010), a cozinha italiana veio a ter uma participação muito expressiva no Brasil, sendo que, inicialmente, apresentava um caráter, sobretudo, doméstico e feminino, e estava geograficamente situada nos limites do que se concebia como "bairros étnicos". Destaque-se que, a princípio, ela era tida como "comida de pobres", sendo vista com desconfiança pelos demais habitantes do país.

Antes da missão dos chefs franceses, o maître d'hôtel possuía uma posição de destaque nos restaurantes de inspiração italiana. Em reportagem da revista Veja de maio de 1975, sobre um restaurante de inspiração italiana, o chef Nicola Angelin não aparecia na fotografia, na qual era conferida uma atenção especial, sobretudo, à atuação do maître d'hôtel. Este, sozinho ou junto ao chef, era conhecido por realizar shows gastronômicos no salão. Nos restaurantes 
italianos prévios à visita de Bocuse e de "La bande", essa também era uma prática comum. Uma tensão entre chefs e maîtres era representada de forma explícita em algumas narrativas, e simbolizava, também, uma outra tensão: aquela entre os trabalhadores de restaurantes italianos e os "vanguardistas" chefs franceses em solo brasileiro.

Afora a oposição entre cuisine à huile e cuisine au beurre, a demarcação dos espaços e dos discursos legítimos se dava também por meio da mobilização de alguns ideais da Nouvelle Cuisine. O movimento rechaçava certos ingredientes, pratos e modos de preparo, a favor da valorização de uma cozinha mais "natural", "leve" e, sobretudo, mais "francesa". Aproximava-se, assim, da dietética, em consonância com transformações mais amplas nos estilos de vida dos habitantes das grandes cidades, incluindo fatores como o aumento do sedentarismo e a preocupação crescente com o corpo e a forma física. Com isso, quase tudo o que caracterizava os pratos de restaurantes de inspiração italiana no país passava, naquele momento, por uma revisão e, por vezes, se tornava alvo de estigma. Pratos volumosos, excessivamente pesados e gordurosos, bem como a transformação exacerbada de ingredientes na prática culinária e o uso de ultraprocessados passavam a ser colocados em xeque e rechaçados na alta cozinha. Estigmatizada, a cozinha italiana era tratada como se passasse por uma massificação crescente, devido a qual perderia o seu valor e a sua importância. Vemos um exemplo disso no trecho da reportagem abaixo:

A verdade é que a riquíssima e celebrada comida italiana ("Eu não sei por que nossa cozinha raramente é lembrada em banquetes oficiais, cedendo lugar à francesa", indaga Dell'Orco) não poderia ignorar as pressões do consumo nem o emprego de produtos industrializados. [...] A inevitável substituição dos alquimistas por equipes de jovens cozinheiras nos grandes restaurantes, a invasão dos enlatados, tudo está contribuindo para uma espécie de "massificação" paradoxalmente perigosa para a comida italiana (Cozinhas italianas, 1975a).

Um dos fundamentos da Nouvelle Cuisine era o de privilegiar a "criatividade" do chef, em oposição ao que se concebia como cozinha clássica francesa. A tradição, portanto, passava a ser alvo de ataques, na medida em que a "nova" cozinha visava revolucionar a gastronomia e superar a "antiga", vista à época como ultrapassada. Na década de 1970, ao mesmo tempo em que as revistas publicavam reportagens sobre a Nouvelle Cuisine e o seu renomado líder, o 
uso da ironia foi recorrente em matérias acerca da vasta cozinha italiana, a qual, a partir do olhar dos franceses, deveria ser também subvertida. Além da mobilização do recurso da ironia, eram frequentes a exotização do consumidor frequentador de restaurantes de tipo italiano encontrados no Brasil e a abordagem estigmatizada da maneira "popular" de se tratar a alimentação.

Nos supermercados, nas estradas congestionadas, nos restaurantes apinhados ou nas butiques da moda, a classe média consome e se diverte. Há sinais isolados de mudanças de hábitos, mas ela faz malabarismos para continuar mastigando, engolindo e seguindo em frente. Um compacto aglomerado de cabeças baixas sobre pratos reforçados. Essa é a imagem mais abrangente do comportamento da classe média nos seus momentos de lazer, nos fins de semana. Mastiga-se com sofreguidão o rodízio corrido (carne à vontade por 22 cruzeiros a cabeça) na churrascaria do Grêmio Futebol Portoalegrense, no Rio Grande do Sul, onde garçons vestidos em azul e negro transitam com dificuldade por entre os quase 400 fregueses acomodados. Mastiga-se em centenas de restaurantes paulistanos. Mastiga-se com vigor nos dezessete restaurantes "italianos" do bairro de Santa Felicidade, em Curitiba, onde um garçom distraído pisa na polenta caída de um prato e continua a trabalhar com os sapatos lambuzados porque a classe média não presta atenção nos detalhes (Consumir é viver, 1975c, p. 57).

Assim, a Nouvelle Cuisine se estabelece no Brasil também em oposição à cozinha italiana, sendo que esta simbolizava, àquela, tudo o que lembrava uma cozinha "popular"11 ou massificada. Nas revistas, a cozinha italiana era representada como se as pessoas se servissem e comessem sempre "em fartura" e "sem formalidades". Os cozinheiros de restaurantes italianos eram retratados como pouco criteriosos no preparo dos pratos, sem qualquer preocupação com o uso de ingredientes frescos, além de pouca ou nenhuma preocupação estética com o prato e as maneiras de os servirem.

A revanche daqueles posicionamentos considerados ofensivos à cultura e à cozinha italianas apareceria em algumas narrativas na década de 1990. Em março de 1993, a revista IstoÉ reportou uma intervenção do presidente da Ordine Ristoratori Professionisti Italiani - ORPI (Ordem dos Donos e Gerentes de Restaurantes Italianos) - no restaurante Massimo, em São Paulo (O fim da nouvelle cuisine, 1993, p. 46). A apresentação dos pratos, reconhecidamente um princípio indiscutível da Nouvelle Cuisine, mas que veio a se difundir em toda a alta cozinha, aparece, nessa matéria, como alvo de crítica dos profissionais italianos. 
Esses alegavam "enterrar" a Nouvelle Cuisine, ao mesmo tempo em que seus pressupostos eram amplamente difundidos nos restaurantes e na imprensa. É na década de 1990 que a gastronomia francesa se estabelece no país, com a emergência da primeira geração de "chefs brasileiros" pós-internacionalização e midiatização. Isso é notório especialmente no uso da linguagem, de materiais e de utensílios, mas, sobretudo, por meio da mobilização de técnicas consagradas francesas na produção "nacional estrangeira" de pratos "brasileiros". Na tentativa de se conter a força desse movimento em direção a um afrancesamento da cozinha praticada aqui, os donos e os cozinheiros de restaurantes italianos manifestavam-se em sua própria defesa, temendo a sua extinção. Travavam uma batalha simbólica com chefs franceses e seus "discípulos".

Revista IstoÉ - Cozinha italiana ou cozinha francesa?

Fasano - Cozinha italiana.

Revista IstoÉ - Por quê?

Fasano - Falo pensando na capacidade de invenção, na imaginação. E também na leveza e na simplicidade. E, ainda, na variedade. Um dos problemas da cozinha francesa está, por incrível que pareça, na sua dependência dos mestres. É lógico que se come maravilhosamente bem na França. Mas a força da palavra dos mestres criou uma maneira de pensar muito uniforme. Graças ao marketing -, e eles são também mestres em marketing -, espalharam-se chefes de cozinha francesa pelo mundo inteiro, todos discípulos deste ou daquele, discípulos de Paul Bocuse, sobretudo, quem tem costas largas. Não lhe bastariam 200 anos de vida para ensinar todos aqueles que se dizem seus alunos (O Primeiro Prato, 1992, p. 8).

Na década de 1970, no Brasil, os cozinheiros tinham pouca centralidade nos restaurantes, ficando atrás, em termos de importância, dos restaurateurs e dos maîtres. A "boa cozinha" italiana era um atributo muito mais ligado ao savoir-faire de mammas - e nonnas - do que de cozinheiros italianos homens. Enquanto a melhor macarronada ou pizza seria aquela elaborada por uma "autêntica" mamma, existia a crença de que o melhor Boeuf Bourguignon certamente era o preparado por um chef francês, preferencialmente renomado. Alguns recursos linguísticos eram usados para representar a prática culinária italiana, com frequência incluindo-se termos como "família", "amizade", "carinho", "amor", "afeto", "história", "tradição", "patrimônio”, etc. O azeite de oliva e o vinho - que estavam quase sempre presentes nas fotografias de res- 
taurateurs e cozinheiros italianos - eram reportados como elementos identitários da cozinha italiana. Eram comuns ataques à manteiga, a qual era representada, a partir do ponto de vista dos profissionais italianos, como sendo um dos maiores símbolos da cozinha francesa.

Além do fato de o azeite de oliva ser usado como marcador distintivo a favor da cozinha italiana, outro recurso social mobilizado nas narrativas era a transmissão intergeracional. Enquanto, na gastronomia francesa, o conhecimento seria transmitido de Bocuse e de outros chefs célebres para seus "discípulos", na italiana ele seria passado "de pai para filho" ou "de mãe para filho". O sobrenome se perpetuava através dos homens da mesma família, contudo, a figura da mamma também era responsável por conferir legitimidade a restaurantes italianos, remetendo à tradição e à família. No caso dos italianos, a tradição como um valor era capitalizada no sentido da existência de uma herança familiar como agregadora de prestígio a itinerários profissionais.

Revista IstoÉ - Esta pretensão de estabelecer uma classificação entre cozinhas não corresponderia a uma visão futebolística das coisas?

Fasano - Talvez. Mas eu acho que as coisas podem ser propostas de uma forma muito objetiva e adequada aos conceitos da vida moderna. Então pergunto, por exemplo: óleo de oliva ou manteiga? Respondo: óleo de oliva. Sou a favor não somente por razões de gosto, mas também porque faz bem à saúde. A manteiga, não.

Revista IstoÉ - Não que a cozinha italiana não use manteiga.

Fasano - Também usa a manteiga. Mas é na cozinha italiana que o óleo de oliva assume o papel que lhe cabe.

Revista IstoÉ - Mas não foi para atender às conveniências do "homem moderno" que nasceu a nouvelle cuisine?

Fasano - Pois aí está: a nova cozinha francesa se inspira na cozinha italiana.

Revista IstoÉ - Mas os franceses dizem que a inspiração foi a cozinha japonesa.

Fasano - No visual, sim. Na apresentação, os japoneses exerceram uma influência muito forte também na cozinha italiana, inclusive em termos de ritmos na elaboração dos pratos e de seu consumo (O Primeiro Prato, 1992, p. 8).

Um recurso também frequentemente mobilizado foi o tempo de atuação profissional, na medida em que os "antigos" estariam à frente dos últimos a chegar. Estes teriam, na visão dos primeiros, "muito a aprender" e menor le- 
gitimidade para falar em nome da alta cozinha. Uma vez que chefs italianos de restaurantes brasileiros encontravam-se, à época, em uma posição hierárquica mais baixa do campo gastronômico, em um cenário de forte expansão e difusão da Nouvelle Cuisine, a prática da fofoca buscava atingir os chefs franceses, na medida em que estes subvertiam a ordem legítima e ocupavam os postos mais altos da hierarquia. ${ }^{12}$

Por todos esses motivos, a recepção da gastronomia francesa no Brasil não se deu de modo simples, sem conflitos. À época da "missão francesa”, a cozinha italiana, há mais de cem anos amplamente presente nos inúmeros restaurantes ao redor do país, era representada nas revistas como "menor", "simples", ligada ao espaço doméstico, à mulher e a práticas "populares" ou mesmo "vulgares". Tais argumentos integravam o discurso dominante, pautado na gastronomia francesa, tida como referência em todo o mundo. Apesar de tais disputas simbólicas, chefs e restaurateurs italianos, bem como chefs estrangeiros radicados no Brasil, uniam-se aos franceses em diferentes modalidades de engajamento, por meio da fundação de associações, da organização de cursos e eventos, em programas televisivos culinários e em muitos outros espaços.

\section{OUTRAS MISSÕES: AS DÉCADAS DE 1980 E 1990}

Na década de 1980 ocorre um fluxo na direção inversa, do Brasil à França: um brasileiro chamado José Hugo Celidônio, acompanhado de editoras da revista Claudia, lidera uma viagem missionária à França a fim de conhecer restaurantes e chefs franceses renomados do período, entrando em contato, dentre outros, com a família Lameloise. Celidônio planeja e organiza a ida e o roteiro da equipe da revista Claudia ao território francês, tendo sido um dos principais intermediários da importação e da adaptação das cozinhas francesa e italiana no Brasil.

Após as primeiras visitas missionárias gastronômicas francesas dos anos 1970, um número representativo de chefs franceses bem reputados passou a migrar para o Brasil. Nas décadas seguintes, investiriam em diversas frentes, em especial em programas de televisão e em restaurantes renomados, sendo que as ideias em jogo pareciam impactar de forma proeminente na formulação do que viria a ser concebido, ao menos em um primeiro momento, como "gastronomia brasileira”. Uma vez que alguns deles foram líderes desse pro- 
Fotografia 2: Os Lameloise e a senhora Loiseau folheando a Revista Claudia.

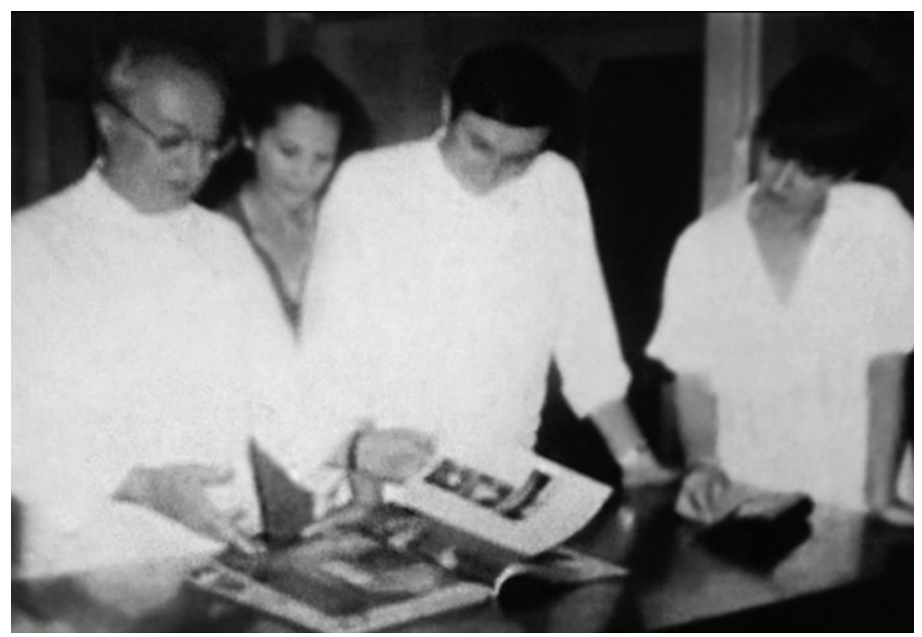

Fonte: A 39ª viagem de Claudia, 1982, p. 312.

cesso, engajaram-se de diferentes maneiras, por meio da criação de associações, cursos e escolas de gastronomia brasileiros, e também da organização de eventos. Conforme uma reportagem da revista IstoÉ, publicada em abril de 1996, tais empreendimentos possuíam, como pano de fundo, uma preocupação objetiva com a formação profissional e o posicionamento da gastronomia brasileira no contexto mundial (Panela profissional, 1996, p. 72). Por meio das associações, investiam na capacitação técnica e cultural de novos profissionais, promovendo cursos gratuitos, intercâmbios com associações extranacionais e a representação brasileira em eventos estrangeiros. Com a chegada de novos chefs e restaurateurs europeus na década de 1990, a diversidade de escolas de gastronomia aumentou exponencialmente.

Em maio de 1995, foram cinco chefs estrangeiros - os franceses Laurent Suaudeau e Emmanuel Bassoleil, o italiano Luciano Boseggia, o suíço Christophe Besse e o argentino Jorge Monti - que tomaram a iniciativa de fundar a Associação Brasileira de Alta Gastronomia, primeiramente com a sigla ABAG, posteriormente ABAGA. Em reportagem de abril de 1996, da revista IstoÉ, os chefs franceses eram representados, nas fotografias e nas narrativas das revistas, como se, em um terreno "vazio" e "inóspito", construíssem um verdadeiro 
império gastronômico no Brasil. Nos eventos da década, os profissionais debatiam acerca dos rumos da profissão de cozinheiro no Brasil e da necessidade de se resgatar a "identidade nacional", por meio da cozinha "autenticamente" brasileira. Chegaram à conclusão, ao final de um desses eventos, de que não havia uma "tradição de cultura gastronômica" no país. A não preocupação em manter as receitas e adaptá-las ou atualizá-las, na visão daqueles chefs, seria um sintoma do risco da extinção da cozinha brasileira. Tal diagnóstico era decorrente de um olhar imperial sobre um país colonizado, ao qual os missionários acreditavam levar a "salvação", por meio da apropriação e da "reinvenção" de cozinhas "tradicionais" e "populares".

Na década de 1990, além dos franceses, outros chefs estrangeiros circularam pelo Brasil. Em 1994, um grupo renomado norte-americano aterrissa em tom de missão gastronômica. Recepcionado por Massimo Ferrari, chef italiano reputado radicado no Brasil, o "exército" de treze chefs do alto escalão gastronômico mundial, sobretudo norte-americano, desembarca em Salvador, na Bahia, visando explorar a culinária regional e articular-se com cozinheiros enraizados no país. No ano seguinte, seria fundada no país a associação nacional de chefs. Estiveram em terras baianas Keith Keogh, o então responsável pela cozinha da Disneylândia; Hans Bueschkens, diretor americano da Wacs, Michael Ty, presidente da American Culinary Federation (ACF), Edwin Brown, vice da ACF e Joe Amendola, embaixador do Instituto Culinário Americano, além do grupo americano que disputaria, dois anos depois, a Olimpíada Gastronômica em Berlim: Keith Coughenour, John Coletta, Duame Hendershot, Kristin Jablonski, Jeffrey Mora, Daniel Dumont e Robert Mancuso. Os chefs circularam por feiras, mercados, restaurantes e fábricas, a fim de garimparem ingredientes e pratos com potencial para serem aceitos no circuito gastronômico internacional.

Outra frente de investimento consistiu na mobilização de recursos políticos, por meio de "gastrodiplomacias", com foco no estreitamento de relações entre chefs de cozinha e chefes de Estado dos países interessados. Em 1997, o então presidente da França Jacques Chirac faz uma visita ao Brasil e elogia a "culinária brasileira". A partir de tal elogio, pratos regionais passaram a fazer parte do cardápio oferecido aos chefes de Estado no protocolo do Itamaraty, ação tomada pelo então presidente brasileiro Fernando Henrique Cardoso. Em uma matéria de abril de 1997, a revista IstoÉ sugeria que a campanha presi- 
dencial de 1994 consistiu em um marco histórico para a aproximação das culinárias regionais com a política nacional, já que, desde aquele momento, diversos restaurantes com menu "brasileiro" proliferaram (Receita Brasileira, 1997, p. 62).

Fotografia 3: Chefs da alta hierarquia gastronômica aterrissam em Salvador (BA).

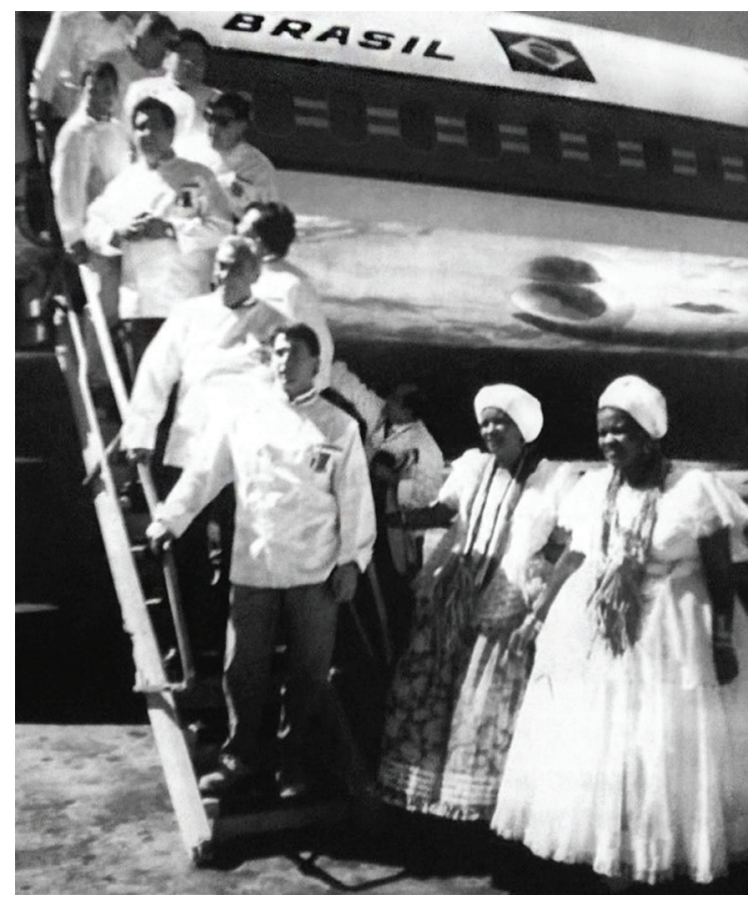

Fonte: O triunfo da moqueca, 1994, p. 82.

A aproximação presidencial com a cozinha foi também marcada pelos trabalhos referentes à alimentação que marcaram o itinerário profissional da antropóloga Ruth Cardoso, primeira-dama do Brasil de janeiro de 1995 a janeiro de 2003. Logo após uma passagem como pesquisadora associada pela École des Hautes Études en Sciences Sociales de Paris (EHESS), no Centre d'Études des Mouvements Sociaux e no Centre International de Recherches sur l'Environnement et le Développement (CIRED), em janeiro de 1985, ela apresentou o trabalho "Les cuisines communautaires et la participation des femmes", 
no Séminaire international La Place des Femmes dans l'Autosuffisance et les Stratégies Alimentaires, promovido pelo Institut Français de Recherche pour le Développement en Coopération (ORSTOM) e pelo Centre International de l'Enfance (CIE) (Cardoso, 1985). Em 1987, no posto de co-coordenadora do Centro Brasileiro de Análise e Planejamento (CEBRAP), desenvolveu também o projeto de pesquisa intitulado "Custos sociais e econômicos das políticas alimentares: mudanças nos comportamentos econômicos e familiares das mulheres da Grande São Paulo”. Uma outra reportagem da revista IstoÉ, de 1999, ligava tal proximidade da primeira-dama à gastronomia com o fato de que foi por iniciativa dela que, pela primeira vez, o Palácio da Alvorada - residência oficial do Presidente do Brasil - contratou um chef de cozinha. Além disso, Laurent Suaudeau, ao atuar como chef do $66^{\circ}$ aniversário de Ruth Cardoso, alertou ao então presidente Fernando Henrique Cardoso: "A comida é a identidade de uma nação. Não podemos ter vergonha do arroz com feijão” (De graça, só o jantar, 1996, p. 72).

\section{Conclusão}

A difusão dos pressupostos da Nouvelle Cuisine, bem como a recepção e a importação da gastronomia francesa no Brasil, não ocorreram de modo simples e sem conflitos, sendo que a atuação missionária liderada por Paul Bocuse gerou repercussões na imprensa e na cultura dos restaurantes da época, notadamente italianos. Aproximadamente um século depois do início da institucionalização da profissão de cozinheiro na França, com o episódio da "missão francesa" nos anos 1970, vemos se desenvolverem, em mídias brasileiras, representações que se assemelham ao processo francês, tais como as tensões, entre agentes com interesses em disputa, sobre o engajamento gastronômico, a defesa da identidade nacional e a demarcação da cozinha profissional em relação à cozinha doméstica e "popular".

Foram peculiares do Brasil também as lutas pela produção do discurso legítimo entre profissionais da cozinha francesa e da italiana - esta sendo, por vezes, alvo de estigma, sobretudo a partir do argumento de que geraria um processo de "massificação" da cozinha. O recurso identitário foi mobilizado de diferentes maneiras, especialmente com base na oposição entre cuisine à l'huile e cuisine au beurre. O popular tem os seus sentidos e os seus usos trans- 
formados em cada contexto em que é representado: nos anos 1970, integra os argumentos de rechaçamento por meio de críticas ao savoir-faire da cozinha italiana, por parte dos franceses e, em 1990, atua como marcador distintivo, em investimentos "gastrodiplomáticos" e como recurso social mobilizado por agentes que militam por determinadas "causas". Para estes, a classificação, a apropriação e a hierarquização do popular legitimam feitos heroicos e, por consequência, também carreiras, legados e discursos gastronômicos.

\section{REFERÊNCIAS}

A 39a VIAGEM DE CLAUDIA. Revista Claudia, São Paulo, nov. 1982, p. 312.

ABARZÚA CUTRONI, Anabella. The North-South Circulation of Experts and Knowledge in Latin America: the Asymmetric Impact of UNESCO Missions between 1945 and 1984. In: DUEDAHL, Poul. A History of UNESCO: Global Actions and Impacts. Londres: Palgrave Macmillan, 2016. pp. 181-198.

BARNES, Christine. Mediating Good Food and Moments of Possibility with Jamie Oliver: Problematising Celebrity Chefs as Talking Labels. Geoforum, v. 84, pp. 169178, 2017.

BEIGEL, Fernanda. Publishing from the Periphery: Structural Heterogeneity and Segmented Circuits. The Evaluation of Scientific Publications for Tenure in Argentina's CONICET. Current Sociology, v. 62, n. 5, pp. 743-765, 2014.

BOURDIEU, Pierre. Vous avez dit "populaire"? Actes de la recherche en Sciences Sociales, v. 46, pp. 98-105, 1983.

BOURDIEU, Pierre. Epilogue: on the Possibility of a Field of World Sociology. In: BOURDIEU, Pierre; COLEMAN, James S. (Orgs.). Social Theory for a Changing Society. Boulder: Westview Press; New York: Russell Sage Foundation, 1999.

BOURDIEU, Pierre. Les conditions sociales de la circulation internationale des idées. Actes de la recherche en Sciences Sociales, v. 145, pp. 3-8, 2002.

BOURDIEU, Pierre. A distinção: crítica social do julgamento. 2. ed. Porto Alegre: Zouk, 2011.

BOURDIEU, Pierre. Sociologie générale. Vol. 1. Cours au Collège de France 1981-1983. Paris: Le Seuil, 2015.

BOURDIEU, Pierre; DELSAUT, Yvette. Le couturier et sa griffe: contribution à une théorie de la magie. Actes de la recherche en Sciences Sociales, v. 1, n. 1, pp. 7-36, 1975.

BUENO, Maria Lúcia. Da gastronomia francesa à gastronomia global: hibridismos e identidades inventadas. Caderno CRH, v. 29, n. 78, pp. 443-462, 2016. 
CAMPBELL, Joseph. The Hero with a Thousand Faces. Novato: New World Library, 2008.

CARDON, Philippe; GARCIA-GARZA, Domingo. L'alimentation: enjeux théoriques et empiriques dans les Amériques. IdeAs, v. 3 (Hiver), 2012.

CARDOSO, Ruth. Les cuisines communautaires et la participation des femmes. SEMINAIRE INTERNATIONAL LA PLACE DES FEMMES DANS L'AUTOSUFFISANCE ET LES STRATEGIES ALIMENTAIRES, Paris, 1985. pp. 619-640.

CASANOVA, Pascale. La République mondiale des lettres. Paris: Le Seuil, 2015.

CHARLE, Christophe (Dir.). Le temps des capitales culturelles: XVIIIe-XXe siècles. Seyssel: Champ Vallon, 2013.

COLLAÇO, Janine Helfst Leicht. Das mammas'as ao restaurante cosmopolita: Um século de restaurantes italianos na cidade de São Paulo (Brasil). Anthropology of food, v. 7, 2010.

COMBESSIE, Jean-Claude. La méthode en sociologie. Paris: La Découverte, 2007.

CONSUMIR É VIVER. Revista Veja, São Paulo, dez. 1975c, p. 57.

COZINHAS ITALIANAS. Revista Veja, São Paulo, mai. 1975a.

DANTO, Arthur. The transfiguration of the commonplace: a philosophy of art. Cambridge, Massachusetts: Harvard University Press, 1981.

DEZALAY, Yves Maurice Pierre; MADSEN, Mikael. Espaços de poderes nacionais, espaços de poderes internacionais: Estratégias cosmopolitas e reprodução das hierarquias sociais. In: CANÊDO, Letícia; TOMIZAKI, Kimi; GARCIA JR., Afrânio (Orgs.). Estratégias educativas das elites brasileiras na era da globalização. São Paulo: Hucitec, 2013. pp. 23-52.

DIETRICH-RAGON, Pascale; LOISON-LERUSTE, Marie; ROUPNEL-FUENTES, Manuella. Articuler les approches quantitative et qualitative. In: PAUGAM, Serge. (Dir.) L'enquête sociologique. Paris: Presses Universitaires de France, 2012. pp. 207-222.

DROUARD, Alain. Histoire des cuisiniers en France: XIXe-XXe siècle. Paris: CNRS Éditions, 2004.

ELIAS, Norbert; SCOTSON, John L. The Established and the Outsiders: a Sociological Enquiry into Community Problems. London: Frank Cass \& Co. Ltd., 1965.

FERGUSON, Priscilla Parkhurst. A Cultural Field in the Making: Gastronomy in 19th Century France. American Journal of Sociology, v. 104, pp. 597-641, 1998.

FERGUSON, Priscilla Parkhurst. La gastronomie en revues. Critique, 685-686, pp. 584-593, 2004.

O FIM DA NOUVELLE CUISINE. Revista Istoé, São Paulo, mar. 1993, p. 46.

GARCIA-PARPET, Marie-France. Mundialização dos mercados e padrões de qualidade: vinho, o modelo francês em questão. Tempo Social, v. 16, n. 2, pp. 129-150, 2004. 
GAULT, Henri; MILLAU, Christian. Gault et Millau se mettent à table. Paris: Stock, 1976.

GARCIA JR., Afrânio. Les disciples de la "mission française" et la réception de l'anthropologie structurale au Brésil. Retour sur un mythe d'origine. Cahiers de la recherche sur l'éducation et les savoirs, Hors-série n. 2, pp. 57-92, 2009.

GINZBURG, Carlo; CASTELNUOVO, Enrico. História da arte italiana. In: GINZBURG, Carlo. A micro-história e outros ensaios. Lisboa: Difel, 1989. pp. 5-118.

DE GRAÇA, SÓ O JANTAR. Revista Istoé, out. 1996. São Paulo, p. 72.

HEILBRON, Johan; JEANPIERRE, Laurent; GUILHOT, Nicolas. Vers une histoire transnationale des sciences sociales. Sociétés Contemporaines, n. 73, pp. 121-145, 2009.

HEILBRON, Johan et al. Indicators of the Internationalization of the Social Sciences and Humanities. Serendipities, v. 1, pp. 131-147, 2017.

JOHNSTON, Josée; RODNEY, Alexandra; SZABO, Michelle. Les gens bien mangent bien: comprendre le répertoire culturel de l’alimentation éthique. IdeAs, v. 3 (Hiver), 2012.

MACIEL, Maria Eunice. Uma cozinha à brasileira. Estudos Históricos, v. 1, n. 33, pp. 25-39, 2004.

LES MAITRES-CUISINIERS DE FRANCE. Revista Marie Claire France, Issy-les-Moulineaux, jun. 1980.

MICELI, Sergio. Intelectuais à brasileira. São Paulo: Companhia das Letras, 2001.

NACCARATO, Peter; LEBESCO, Kathleen. Culinary Capital. London: Berg Publishers, 2012.

NAULIN, Sidonie. Les médias et la constitution d'un "monde de la gastronomie" (1870-1940). Le Temps des médias, Nouveau Monde Editions, v. 24, n. 1, pp. 26-43, 2015.

NIEDERLE, Paulo André; SCHNEIDER, Evandro Pedro. L'inclusion d'éco-conditionnalités dans les indications géographiques brésiliennes: enjeux et contradictions. Brésil(s): Sciences humaines et sociales, v. 13, pp. 1-11, 2018.

PAGÈS, Dominique. Figures du Chef Cuisinier. Seconde partie: d'une autorité civique revendiquée aux engagements citoyens et collaboratifs des "mangeurs". Quaderni, n. 95, pp. 95-114, 2018.

PANELA PROFISSIONAL. Revista Istoé, São Paulo, abr. 1996, p. 72.

PANOFSKY, Erwin. Meaning in the Visual Arts. Chicago: University of Chicago Press, 1983.

PANOFSKY, Erwin; HöRNKE, Wolf. Arquitetura gótica e escolástica: sobre a analogia entre arte, filosofia e teologia na Idade Média. São Paulo: Martins Fontes, 2001.

PINTO, Louis. Du bon usage de La Distinction. In: COULANGEON, Philippe; DUVAL, Julien (Orgs.). Trente ans après La Distinction, de Pierre Bourdieu. Paris: La Découverte, 2013. pp. 83-95. 
PIPER, Nick. Jamie Oliver and Cultural Intermediation. Food, Culture \& Society, v. 18, n. 2, pp. 245-264, 2015.

POULAIN, Jean-Pierre. La gastronomisation des cuisines de terroir: sociologie d'un retournement de perspective. In: ADELL, Nicolas; POUCHER, Yves (Dirs.). Transmettre, quel(s) patrimoine(s)?: Autour du patrimoine culturel inmatériel. Paris: Houdiard, 2011. pp. 239-248.

POULAIN, Jean-Pierre. A gastronomização das culturas locais. In: WOORTMANN, Ellen; CAVIGNAC, Julie A. (Orgs.). Ensaios sobre a Antropologia da alimentação: saberes, dinâmicas e patrimônios. Natal: EDUFRN, 2016. pp. 33-54.

PREVIATTI, Débora. Chefs à brasileira: o processo de formação de um campo gastronômico (1961-2018). Tese (Doutorado em Sociologia Política) - Centro de Filosofia e Ciências Humanas, Universidade Federal de Santa Catarina. Florianópolis, 2019. $411 \mathrm{pp}$.

O PRIMEIRO PRATO. Revista Istoé, São Paulo, out. 1992, p. 8.

PULICI, Carolina. A alimentação solene e parcimoniosa: práticas gastronômicas como fonte de distinção das elites paulistanas. In: PULICI, Carolina; FERNANDES, Dimitri (Orgs.). As lógicas sociais do gosto. São Paulo: Editora Unifesp, 2019. pp. 41-62.

QUESADA, Fernando. La Universidad desconocida. El Convenio Universidad de Chile-Universidad de California y la Fundación Ford. Mendoza: Facultad de Filosofía y Letras de la Universidad Nacional de Cuyo, 2015.

RECEITA BRASILEIRA. Revista Istoé, São Paulo, abr. 1997, p. 62.

RECEITAS DO MELHOR COZINHEIRO do mundo. Revista Claudia, São Paulo, set. 1977, p. 136.

SR. RESTAURANTE. Revista Veja, São Paulo, ago. 1975b, p. 42.

SAPIRO, Gisèle. L'espace intellectuel en Europe: De la formation des États-nations à la mondialisation. XIXe-XXe siècles. Paris: La Découverte, 2009.

SAPIRO, Gisèle. How do Literary Works Cross Borders (or Not): A Sociological Approach to World Literature. Journal of World Literature, v. 1, n. 1, pp. 81-96, 2016.

SAPIRO, Gisèle. Entre o nacional e o internacional: o surgimento histórico da sociologia como campo. Sociedade e Estado, v. 33, n. 2, pp. 349-372, 2018.

SCHWARCZ, Lilia Moritz; SIMIONI, Ana Paula Cavalcanti. La colonie des artistes français à Rio de Janeiro en 1816: un passé recomposé. Brésil(s): Sciences humaines et sociales, v. 10, pp. 1-8, 2016.

STEINMETZ, George. The Historical Sociology of Historical Sociology. Germany and the United States in the Twentieth Century. Sociologica, v. 3, pp. 1-28, 2007.

SUPPO, Hugo. Intelectuais e artistas nas estratégias francesas de "propaganda cultural" no Brasil (1940-1944). Revista de História, n. 133, pp. 75-88, 1995.

SUPPO, Hugo. A política cultural da França no Brasil entre 1920 e 1940: o direito e o avesso das missões universitárias. Revista de História, n. 142-143, pp. 309-345, 2000. 
TAUNAY, Afonso d'Escragnolle. A missão artística de 1816. Brasília: Editora da UnB, 1983.

TISSOT, Sylvie. "Anything but Soul Food". Goûts et dégoûts alimentaires chez les habitants d'un quartier gentrifié. In: COULANGEON, Philippe; DUVAL, Julien (Orgs.). Trente ans après La Distinction, de Pierre Bourdieu. Paris: La Découverte, 2013. pp. 141-152.

O TRIUNFO DA MOQUECA. Revista Istoé, São Paulo, jun. 1994, p. 82.

\section{NOTAS}

${ }^{1}$ O presente trabalho foi realizado com apoio da Coordenação de Aperfeiçoamento de Pessoal de Nível Superior - Brasil (CAPES) - Código de Financiamento 001. Este artigo é derivado da tese de doutorado da autora (Previatti, 2019).

${ }^{2} \mathrm{~A}$ visita decorreu não de uma iniciativa governamental, mas dos próprios chefs sob a liderança de Paul Bocuse.

${ }^{3}$ Ver, sobre esse assunto, Ginzburg e Castelnuovo (1989).

${ }^{4}$ Sobre esforços que vêm sendo dedicados à internacionalização das ciências sociais, ver Bourdieu (1999), Heilbron et al. (2017) e Sapiro (2009).

5 Sobre esta questão, ver Tissot (2013), acerca do papel da "ethnic food", da "fusion food" e de outras "cozinhas do mundo" em restaurantes de Nova York.

${ }^{6}$ Sobre este assunto, conferir Charle (2013, p. 15).

${ }^{7}$ Ver, sobre esse assunto, Campbell (2008).

${ }^{8}$ A partir dos aportes de Bourdieu (1983), o termo "popular" é considerado locução definida relacionalmente para distinguir o conjunto de tudo o que é excluído da cozinha legítima.

9 Conforme Naulin (2015), o "discurso gastronômico" na França, de onde advém grande parte das regras do espaço gastronômico mundial, passou, pouco a pouco, a se apropriar e a incorporar um "discurso regionalista".

${ }^{10}$ Para maiores detalhes sobre esse tema, ver Danto (1981) e Bourdieu e Delsaut (1975).

11 "Le peuple n'est que quelque chose qui permet de maximiser la puissance de discrédit que l'on peut exercer contre des adversaires intellectuels." (Bourdieu 2015, p. 614). "O povo nada mais é do que aquilo que permite maximizar o poder de descrédito a ser usado contra adversários intelectuais." (tradução nossa).

${ }^{12}$ Sobre o papel da fofoca, ver Elias e Scotson (1965).

Artigo submetido em 12 de dezembro de 2020. Aprovado em 04 de maio de 2021. 